\title{
Journal of Pediatric Neurology \&

\section{Children in the US are at High Risk for Psychiatric Disorders: Early Monitoring by Parents May Enhance Awareness and Treatment}

\section{Robert M. Post}

George Washington University School of Medicine, Bipolar Collaborative Network, Bethesda, United States

*Corresponding author: Robert M. Post, Professor of Psychiatry, George Washington University School of Medicine, Bipolar Collaborative Network, Bethesda, United States; Tel: 240-888-1317; Fax: 301-530-8247 E-mail: robert.post@speakeasy.net

Received date: Feb 11, 2016; Accepted date: Mar 26, 2016; Published date: April 6, 2016

Copyright: ( 2016 Robert M. Post. This is an open-access article distributed under the terms of the Creative Commons Attribution License, which permits unrestricted use, distribution, and reproduction in any medium, provided the original author and source are credited.

\section{Introduction}

\section{Magnitude of the Problem}

In a recent study by Axelson et al. [1] children of a parent with bipolar disorder or community controls without a bipolar diagnosis were followed prospectively for 7 years. A very high incidence of childhood psychiatric illness was observed in both groups. The offspring of a parent with bipolar disorder had a major psychiatric diagnosis $74.2 \%$ of the time, while the offspring of the controls still had a disturbingly high incidence of illness of $48.4 \%$. The lifetime diagnosis rates as listed in Table 2 in Axelson et al. [1] (in the high risk children versus the controls) included: an anxiety disorder (39.9\% vs $21.8 \%$ ); major depressive $(32.0 \%$ vs $14.9 \%)$; $\mathrm{ADHD}(30.7 \%$ vs $18.1 \%)$; disruptive behavioral disorder $(27.4 \%$ vs $15.3 \%)$; substance use disorders (19.9\% vs $10.1 \%)$; and full to sub threshold bipolar disorder (22.5\% vs $2.0 \%)$.

The offspring of a parent with unipolar depression are also at high risk for a psychiatric diagnosis. After following children of a parent with unipolar depression or comparison controls for 20 years, Weissman et al. [2] also saw a high incidence of a range of illnesses similar to those seen with a bipolar parent. Offspring of a parent with depression had a major psychiatric diagnosis $83 \%$ of the time, while the offspring of the controls again had a considerable incidence of illness of $56 \%$ [2].

These data in prospective follow up studies are also supported by data in epidemiological studies in the US. In the National Comorbidity Study [3] adolescents (aged 13 to 18) $49.5 \%$ had a major psychiatric diagnosis, and, similarly, $49.2 \%$ were diagnosed in the Great Smokey Mountains study [3]. Some types of childhood psychiatric illness may be more prevalent in the US than in many other countries. Data from our international network indicate that patients with bipolar illness from the US have an earlier age of onset of bipolar disorder and a more pernicious course of illness than those from the Netherlands and Germany [4]. The findings of more childhood onset of bipolar disorder in the US compared to Europe have been replicated by Bellivier et al. [5] and Etain et al. [6].

\section{Potential Reasons for the High Incidence in the US}

Two of the major risk factors for early onset bipolar disorder genetic vulnerability and psychosocial adversity in childhood - are also more prevalent in the US than in Europe [4]. The greater genetic vulnerability in the US appears to have been present for several generations. We found that the parents and grandparents of our patients with bipolar disorder from the US had more depression, bipolar disorder, alcohol and substance abuse, and "other" illness than those from Europe $[7,8]$. Interesting, this increase in familial loading for psychiatric illness was also directly related to an increased incidence of psychiatric illness in the offspring of the patients with bipolar disorder. The offspring of patients in the US had a psychiatric illness in $46.3 \%$ compared to those from Europe who had a $16.1 \%$ incidence of illness. These lower incidences than those seen by Axelson et al. [1] were based on patient report and not prospective diagnostic interviews or long term follow up. The US offspring had significantly $(\mathrm{p}<0.001)$ more depression, bipolar disorder, and "other" illnesses compared to the Europeans [9].

Together, these data suggest that four generations of those in the US had more psychiatric illness than the Europeans. The reasons for this increased genetic/familial vulnerability are not well delineated, but we have observed 3 times more assortative mating for a mood disorder (marrying another with a mood disorder) in the US than in Europe. We also found that the spouses of the patients from the US had more illness than those from the Netherlands and Germany. Illness vulnerability from both parents could contribute to the increased illness in the US compared to European offspring.

At the same time, patients from the US also experienced more adversity in childhood (verbal, physical, or sexual abuse) than the Europeans [10]. The presence of such abuse in childhood, even the occurrence of verbal abuse alone, is associated with an earlier onset of bipolar disorder and a more difficult course thereafter [11].

\section{Implications for Screening and Referral}

The findings based upon several different methods of ascertainment are striking and suggest that as many as $3 / 4$ of children of a parent with a mood disorder and $1 / 2$ of those in the general community in the US will have a major psychiatric diagnosis upon long term follow-up. The depression and bipolar diagnoses are particularly problematic as early onset mood disorders run a more difficult course than those of adult onset and are associated with longer delays to first treatment [12]. Both early onset bipolar disorder and the duration of the delay to first treatment are independent predictors of a poor outcome in adulthood [13].

The other diagnoses reported in the offspring in the high risk studies are also associated with considerable short and long term morbidity. Yet in the Weissman study [2] a minority of those with any diagnosis were in any kind of treatment. In an epidemiological study, children with a bipolar disorder diagnosis were treated with any medications $18 \%$ of the time, and of those treated only $44 \%$ received a specialty referral [14]. However, $90 \%$ of those with a bipolar diagnosis had severe impairment [15]. 
Given these findings of high illness burden with lifelong implications for health and well being in both high risk children and those in the community in the US, new approaches to public and clinician awareness and to early diagnosis and treatment are indicated. We have started a Child Network as one way to begin to address these problems (see www.bipolarnews.org; click on Child Network). In the Child Network, parents of children (aged 2-12) with mood or behavioral problems can rate their child on a weekly basis on the severity of symptoms of depression, anxiety, ADHD, oppositional behavior, and mania on a secure web site. Ratings can be printed out longitudinally, which will facilitate assessment of symptom course and need for treatment or referral. This has the advantage of giving a longitudinal assessment of symptoms commonly experienced in childhood disorders. It also helps relieve some of the burden on busy physicians, as parents are supplying the bulk of the effort and time required for longitudinal assessment. If high levels of symptoms persist, the child can then be treated or referred as indicated.

\section{Treatment Principles}

Childhood depression and anxiety respond well to psychotherapy, while stimulants and related agents are the well-known treatment of choice for ADHD. However, if the child has bipolar disorder, most authorities agree that lithium, anticonvulsant mood stabilizers (valproate, carbamazepine or lamotrigine), or atypical antipsychotics are the first line treatments [16-19]. Then, only after mood has been stabilized, should one add low doses of stimulants as necessary for any residual ADHD symptoms. In very young children there is a high cooccurrence of ADHD with bipolar disorder. In those with ADHD, additional symptoms suggestive of a co-occurring bipolar disorder include: brief or extended periods of euphoria; decreased need for sleep; extremes of irritability and aggression; suicidal or homicidal ideation or actions; hallucinations or delusions; or inappropriate sexuality [20].

If the child is being treated, ratings by the parent in the Child Network will also help assess the degree of response to psychosocial or pharmacological treatment. The informed consent and study entry is available at www.bipolarnews.org, click on Child Network. It is hoped that the Child Network will also be able to provide information back to the community about how very young children are actually being treated and how well it is working. That physicians also assess the health of the child's parents is an important factor in the child's health. Studies have shown that if mothers with depression are treated to remission, their offspring have fewer and less severe psychiatric illnesses than mothers whose depression has be incompletely treated [21]. An excellent, brief, validated screening tool for adults My Mood Monitor (M-3) is available on line at www.whatsmyM3.com.

Shonkoff and Garner [22] have advocated for pediatricians to become the primary guardians of children health. They emphasize that toxic stress in childhood (verbal, physical, and sexual abuse or neglect) is a major cause of both medical and psychiatric problems in adulthood. Most children with psychiatric problems are seen by pediatricians and other primary care physicians [23] and having a ready source of parent-generated symptom monitoring will facilitate the process of screening, treatment, or referral.

Pediatricians and child and adult psychiatrists should be aware of the high burden of illness in those at increased risk because of a parental history of unipolar or bipolar disorder, as well as those with prodromal symptoms or a history of childhood adversity. Axelson et al
[1] recommend earlier intervention in children at high risk because of a parent with bipolar disorder in an attempt to slow the rate of conversion to full-blown bipolar disorder. Children initially diagnosed with depression, a disruptive behavioral disorder, or subthreshold manic symptoms (ie those with only brief bursts of mania; what many have labeled bipolar not otherwise specified or BP-NOS) were the ones who were most likely to convert to full blown mania upon follow up. Being alert to and treating premonitory symptoms and syndromes may head-off the emergence of more full-blown illness. However, tracking and treating a child with any of the major psychiatric illnesses revealed by persistently high weekly ratings in the Child Network of depression, anxiety, oppositional defiant disorder, and ADHD would be valuable in their own right. Other screening instruments include the Child Behavioral Check List (CBCL) [24-28] and the Mood Disorder Questionnaire for adolescents [29].

\section{Evidence of Effectiveness of Early Intervention}

If a child has two or three vulnerability factors, including 1) parents or grandparents with psychiatric illness; 2) a history of early adversity, abuse, or neglect: or 3) has already become symptomatic, clinical awareness should be further heightened [10]. If a child has a fullsyndrome depression or anxiety disorder or a BP-NOS diagnosis, psychotherapeutic treatment is indicated and pharmacological treatment may be necessary as well. For example, Miklowitz et al. [30] found that family focused treatment (FFT) was superior to treatment as usual (TAU) in children with a diagnosis of depression or anxiety who also had a positive family history of bipolar disorder. The effects of FFT were largest in families with high levels of expressed negative emotion.

Early expert treatment can change the course of illness for the better as amply demonstrated by Kessing et al. [31]. Patients with a first hospitalization for mania were randomized to 2 years of specialty clinic treatment versus TAU. Specialty clinic treatment included: posthospital transition counseling; psycho-education; symptom recognition and monitoring, psychotherapy, and pharmacotherapy. Not only were there markedly fewer relapses initially over the first 2 years in the specialty clinic group, but these differences persisted and were magnified over the subsequent 4 years even though all patients had returned to TAU after 2 years. These data together with a large number of controlled studies showing superior effects of randomized psychotherapy/psycho-education compared to TAU in children and adults with bipolar disorder [32-34], provide strong evidence for the benefits of multi-modal psychotherapeutic and pharmacological treatment.

Childhood onset psychiatric illnesses are not benign and deserve the same attention and care by an integrated treatment team that is standard practice for other serious childhood medical disorders, such as diabetes, cancer, rheumatoid arthritis, or epilepsy. With the evidence now available that illness trajectory can be dramatically improved with expert treatment [31,35] providing this type of comprehensive treatment on a routine basis for children with major psychiatric illness is highly desirable. Children in the US are at even greater risk for serious psychiatric illness than in many European countries, and special attention to youth in the US is indicated [4].

Complicating this endeavor, are the relative lack of experts in many communities in the pharmacotherapy or psychotherapy of childhood bipolar disorder and the existence of strong feelings and stigma about recognizing and treating very young children with bipolar and related 
disorders. Parents can help overcome some of these difficulties by taking a proactive role in completing the once weekly brief longitudinal assessment of a range of common symptoms experienced by children using the tools available in the Child Network. Parents can then take these printed-out symptom graphs and charting of any drug or psychotherapy treatment to their physicians to assist them in the early recognition of the pattern of symptoms, need for treatment, or response to treatment.

A new public health and clinical treatment research agenda is sorely needed to better inform families and clinicians about optimal treatment of these disorders in young children. In the meantime, clinicians can encourage parents of young children to join the Child Network so that better longitudinal information can be brought to bear on treatment decisions and assessments of treatment effectiveness. There is an enormous burden of psychiatric illness in young children in the US, and earlier recognition and treatment may lessen the longterm adverse consequences.

\section{References}

1. Axelson D, Goldstein B, Goldstein T, Monk K, Yu H, et al. (2015) Diagnostic Precursors to Bipolar Disorder in Offspring of Parents With Bipolar Disorder: A Longitudinal Study. Am J Psychiatry 172: 638-646.

2. Weissman MM, Wickramaratne P, Nomura Y, Warner V, Pilowsky D, et al. (2006) Offspring of depressed parents: 20 years later. Am J Psychiatry 163: 1001-1008.

3. Copeland W, Shanahan L, Costello EJ, Angold A (2011) Cumulative prevalence of psychiatric disorders by young adulthood: a prospective cohort analysis from the Great Smoky Mountains Study. J Am Acad Child Adolesc Psychiatry 3: 252-261.

4. Post RM, Altshuler L, Kupka R, McElroy S, Frye MA, et al. (2014) More pernicious course of bipolar disorder in the United States than in many European countries: implications for policy and treatment. J Affect Disord 160: 27-33.

5. Bellivier F, Etain B, Malafosse A, Henry C, Kahn JP, et al. (2014) Age at onset in bipolar I affective disorder in the USA and Europe. World J Biol Psychiatry 15: 369-376.

6. Etain B, Lajnef M, Bellivier F, Mathieu F, Raust A, et al. (2012) Clinical expression of bipolar disorder type I as a function of age and polarity at onset: convergent findings in samples from France and the United States. J Clin Psychiatry 73: e561-566.

7. Post RM, Altshuler L, Kupka R, McElroy SL, Frye MA, et al. (2015) Multigenerational Positive Family History of Psychiatric Disorders Is Associated With a Poor Prognosis in Bipolar Disorder. J Neuropsychiatry Clin Neurosci 4: 304-310.

8. Post RM, Leverich GS, Kupka R, Keck PE Jr, McElroy SL, et al. (2015) Increases in multiple psychiatric disorders in parents and grandparents of patients with bipolar disorder from the USA compared with The Netherlands and Germany. Psychiatr Genet 5: 194-200.

9. Post RM, Altshuler LL, Kupka R, McElroy SL, Frye MA, et al. (2016) More illness in offspring of bipolar patients from the U.S. compared to Europe. J Affect Disord 191: 180-186.

10. Post RM, Altshuler L, Leverich G, Nolen W, Kupka R, et al. (2013) More stressors prior to and during the course of bipolar illness in patients from the United States compared with the Netherlands and Germany. Psychiatry Res 210: 880-886.

11. Post RM, Altshuler LL, Kupka R, McElroy SL, Frye MA, et al. (2015) Verbal abuse, like physical and sexual abuse, in childhood is associated with an earlier onset and more difficult course of bipolar disorder. Bipolar Disord 17: 323-330.

12. Post RM, Leverich GS, Kupka RW, Keck PE Jr, McElroy SL, et al. (2010) Early-onset bipolar disorder and treatment delay are risk factors for poor outcome in adulthood. J Clin Psychiatry 71: 864-872.
13. Grigoroiu-SerbÄfnescu M, Christodorescu D, Jipescu I, Totoescu A, Marinescu E, et al. (1989) Psychopathology in children aged 10-17 of bipolar parents: psychopathology rate and correlates of the severity of the psychopathology. J Affect Disord 16: 167-179.

14. Merikangas KR, He JP, Rapoport J, Vitiello B, Olfson M (2013) Medication use in US youth with mental disorders. JAMA Pediatr 167: 141-148.

15. Chang KD, Steiner H, Ketter TA (2000) Psychiatric phenomenology of child and adolescent bipolar offspring. J Am Acad Child Adolesc Psychiatry 39: 453-460.

16. Kowatch RA, Fristad M, Birmaher B, Wagner KD, Findling RL, et al. (2005) Treatment guidelines for children and adolescents with bipolar disorder. J Am Acad Child Adolesc Psychiatry 44: 213-235.

17. Geller B, Luby JL, Joshi P, Wagner KD, Emslie G, et al. (2012) A randomized controlled trial of risperidone, lithium, or divalproex sodium for initial treatment of bipolar I disorder, manic or mixed phase, in children and adolescents. Arch Gen Psychiatry 69: 515-528.

18. Post RM, Altshuler LL, Frye MA, Suppes T, Keck PE Jr, et al. (2010) Complexity of pharmacologic treatment required for sustained improvement in outpatients with bipolar disorder. J Clin Psychiatry 71: 1176-1186.

19. Nandagopal JJ, DelBello MP, Kowatch R (2009) Pharmacologic treatment of pediatric bipolar disorder. Child Adolesc Psychiatr Clin N Am 18: 455-469.

20. Post RM, Luckenbaugh D, Findling RL (2014) Number, Severity, and Quality of Symptoms Discriminate Early Onset Bipolar Disorder From ADHD. Psy Annals 9: 416-422.

21. Wickramaratne P, Gameroff MJ, Pilowsky DJ, Hughes CW, Garber J, et al. (2011) Children of depressed mothers 1 year after remission of maternal depression: findings from the STAR ${ }^{\star} \mathrm{D}$-Child study. Am J Psychiatry 168: 593-602.

22. Shonkoff JP, Garner AS (2012) Committee on Psychosocial Aspects of Child and Family Health; Committee on Early Childhood, Adoption, and Dependent Care; Section on Developmental and Behavioral Pediatrics. The lifelong effects of early childhood adversity and toxic stress. Pediatrics 129: e232-246.

23. Anderson LE, Chen ML, Perrin JM, Van Cleave J (2015) Outpatient Visits and Medication Prescribing for US Children With Mental Health Conditions. Pediatrics 136: e1178-1185.

24. Achenbach TM, Rescorla LA (2000) Manual for the ASEBA Preschool Forms \& Profiles, R.C.f.C. University of Vermont.

25. Achenbach TM, Rescorla LA (2001) Manual for the ASEBA School-Age Forms and Profiles, R.C.f.C. University of Vermont.

26. Mick E, Biederman J, Pandina G, Faraone SV (2003) A preliminary metaanalysis of the child behavior checklist in pediatric bipolar disorder. Biol Psychiatry 53: 1021-1027.

27. Sood AB, Razdan A, Weller EB, Weller RA (2005) How to differentiate bipolar disorder from attention deficit hyperactivity disorder and other common psychiatric disorders: a guide for clinicians. Curr Psychiatry Rep 2: $98-103$.

28. Turgay A (2004) Aggression and disruptive behavior disorders in children and adolescents. Expert Rev Neurother 4: 623-632.

29. Wagner KD, Hirschfeld RM, Emslie GJ, Findling RL, Gracious BL, et al. (2006) Validation of the Mood Disorder Questionnaire for bipolar disorders in adolescents. J Clin Psychiatry 67: 827-830.

30. Miklowitz DJ, Schneck CD, Singh MK, Taylor DO, George EL, et al. (2013) Early intervention for symptomatic youth at risk for bipolar disorder: a randomized trial of family-focused therapy. J Am Acad Child Adolesc Psychiatry 52: 121-131.

31. Kessing LV, Hansen HV, Hvenegaard A, Christensen EM, Dam H, et al (2013) Treatment in a specialised out-patient mood disorder clinic v. standard out-patient treatment in the early course of bipolar disorder: randomised clinical trial. Br J Psychiatry 202: 212-219. 
Citation: Post RM (2016) Children in the US are at High Risk for Psychiatric Disorders: Early Monitoring by Parents May Enhance Awareness and Treatment. J Pediatr Neurol Med 1: 1000110. doi:10.4172/2472-100x.1000110

Page 4 of 4

32. Vallarino M, Henry C, Etain B, Gehue LJ, Macneil C, et al. (2015) An evidence map of psychosocial interventions for the earliest stages of bipolar disorder. Lancet Psychiatry 2: 548-563.

33. Scott J, Colom F, Vieta E (2007) A meta-analysis of relapse rates with adjunctive psychological therapies compared to usual psychiatric treatment for bipolar disorders. Int J Neuropsychopharmacol 1: 123-129.
34. Swartz HA, Swanson J (2014) Psychotherapy for Bipolar Disorder in Adults: A Review of the Evidence. Focus (Am Psychiatr Publ) 12: 251-266.

35. van der Voort TY, van Meijel B, Goossens PJ, Hoogendoorn AW, Draisma S, et al. (2015) Collaborative care for patients with bipolar disorder: randomised controlled trial. Br J Psychiatry 206: 393-400. 